\title{
The Endogeneity of Employment Adjustment Costs: The Tradeoff between Efficiency and Flexibility
}

\author{
Charles A. Fleischman* \\ Division of Research and Statistics \\ Board of Governors of the Federal Reserve System \\ Mail Stop 80 \\ Washington, DC 20551 \\ (202) 452-6473 \\ cfleischman@frb.gov
}

December 1996

\begin{abstract}
This paper models a firm's choice of employment adjustment costs as one component of its choice of production process. In making a one-time choice of production process, firms tradeoff increased flexibility--the reduced cost of changing levels of production--against the diminished efficiency of producing a given level of output. The model predicts that firms facing greater volatility in expected employment choose production processes that entail relatively low costs of adjusting employment. Using estimates of adjustment costs and employment volatility for four-digit manufacturing industries, the paper finds empirical support for the model: Among four-digit industries facing similar choices of production process, those with more volatile employment tend to have lower costs of adjusting employment. Moreover, the paper finds that interindustry heterogeneity in the amplitude of deterministic seasonal fluctuations in employment is more important than the variance of stochastic employment fluctuations in explaining the choice of adjustment costs.
\end{abstract}

\footnotetext{
*This paper is a revised version of chapter 3 of my doctoral dissertation at the University of Michigan. I would like to thank Bob Barsky, Susanto Basu, Marcello Estevão, Carol Evans, Bruce Fallick, David Hummels, Spencer Krane, Jonathan Parker, John Roberts, Valerie Suslow, Bill Wascher, and participants at seminars at the Federal Reserve Board and the University of Michigan for many helpful comments and discussions, and the Bureau of Labor Statistics for providing me with unpublished data from the establishment survey. I would especially like to thank Matthew Shapiro for his insights and suggestions. Of course, I am responsible for any remaining errors. In addition, the views expressed in this paper are those of the author, and not necessarily those of the Federal Reserve Board or its staff.
} 



\section{Introduction}

Manufacturing firms face myriad choices in designing their plants and in choosing production processes. When future demand is uncertain or output varies seasonally, firms value flexibility--the ability to produce over a range of output levels without sharply increasing marginal or average costs--in their production process. Increased flexibility, however, is not free. Stigler (1939), Fuss and McFadden (1978), and Beaulieu, MacKieMason, and Miron (1992) discuss the tradeoff between flexibility and efficiency in the choice of production processes. These authors argue that, everything else equal, firms that face greater variability in product demand will choose more flexible production processes than firms that face lesser variability in product demand. Stigler (1939) describes the nature of this tradeoff:

[W]e have tacitly assumed that technology dictates a single most desirable arrangement of the fixed plant which is independent of fluctuations in output. In fact, of course, this is rarely, if ever, true. Adaptability can also be built into a plant, and entrepreneurs in trades where fluctuations are frequent and great will endeavor to secure flexibility in their operations. But, flexibility will not be a "free good": A plant certain to operate at X units of output will surely have lower costs at that output than a plant designed to be passably efficient from $\mathrm{X} / 2$ to $2 \mathrm{X}$ units per week. ${ }^{1}$

In this paper, I argue that when choosing their production processes, firms consider the costs of reorganizing production associated with moving between different levels of output in addition to the static considerations stressed by Stigler (1939), Fuss and McFadden (1978), and Beaulieu, et al. (1992). ${ }^{2}$ Reorganization costs are an important part of the internal costs of adjusting production worker employment and range from the costs involved in reformulating production teams and workers' tasks when adding (removing) workers to (from) a shift to those associated with reallocating production across plants after an increase or

\footnotetext{
${ }^{1}$ Stigler (1939, reprinted), p. 125.

${ }^{2}$ Stigler (1939) and Fuss and McFadden (1978) are concerned primarily with issues affecting the substitutability between fixed and variable factors, and, therefore, the slope of the marginal cost and average variable cost curves. Beaulieu, et. al. (1992) assume that marginal cost is nearly flat up to a binding capacity constraint and focus on the choice of productive capacity, which thus determines the range of feasible levels of production.
} 
decrease in the number of plants operating. In turn, these costs depend on the myriad decisions firms make in choosing a plant design, including the degree of worker specialization, the capital-to-labor ratio, the minimum practical scale of production, and the plant size.

In this paper, I extend the model developed in Fleischman (1996) to allow for endogenous adjustment costs. The parameter representing the firm's costs of adjusting the level of production worker employment is a summary statistic for these reorganization costs. In the model, a firm can vary production worker labor input by changing the number of production workers or the number of hours per production worker. I assume that a firm only incurs adjustment costs when it changes the number of production workers; when it varies production by changing hours per worker it does not incur any adjustment costs. However, each firm faces a roughly U-shaped schedule of hourly production worker compensation, so that it is costly to allow hours per worker to deviate from their long-run cost-minimizing level.

I propose that endogeneity of adjustment costs can explain much of the substantial heterogeneity in adjustment costs within the manufacturing sector found in Fleischman (1996). I treat each four-digit SIC manufacturing industry as a representative firm and I allow each of these representative firms to make a one-time choice of production process that determines the costs of adjusting employment. The firm chooses its adjustment costs for production worker employment as part of its choice of production process by equating the marginal benefit of increased flexibility, which includes reductions in both the costs of adjusting employment and the costs of variations in weekly hours, with the marginal cost of increased flexibility, which includes the loss of productive efficiency from choosing a production process that is less than fully efficient around the firm's statically optimal level of output. In the model, a firm that faces greater volatility in expected employment has a higher marginal benefit of flexibility. Therefore, everything else equal, a firm that faces highly variable labor demand chooses a production process that allows for more flexible and less costly changes in employment at the expense of some loss of efficiency.

While the model focuses on interindustry differences in the nature of fluctuations in labor demand as the primary explanation for heterogeneity in adjustment costs, this 
heterogeneity may also be driven by interindustry differences in technological opportunities, including the ability to use variations in inventory holdings to smooth production. ${ }^{3}$ In many food processing industries, for example, the level of production is tied to the availability of raw agricultural inputs and firms find it excessively costly to hold buffer-stocks of final goods inventories. A food processing firm may operate most of the year with a small number of workers and during peak (harvest) season increase production predominantly by adding workers--rather than by increasing hours per worker. Because of the magnitudes involved, it would not be possible for firms in these industries to satisfy variations in their demand for total production worker hours by varying hours per worker. ${ }^{4}$ The ability to vary output substantially over the year without incurring large costs of adjusting production worker employment, therefore, is crucial in the food processing industries, suggesting that these industries face a different tradeoff between efficiency and flexibility in choosing their adjustment costs.

In the apparel industries, manufacturing is structured around single workers operating individual sewing machines. Because workers are engaging in essentially similar activities, production need not be reorganized when firms change output by increasing or decreasing the number of production workers. With this type of production process, the costs of adjusting employment are low. As a result, firms in the apparel industries predominantly change output by changing the number of production workers rather than by changing hours per worker. ${ }^{5}$

In contrast, firms in durable goods industries tend to operate production processes where workers performing more specialized tasks or where several workers jointly operate a single piece of capital. Automobile production, for example, is organized around long assembly lines, with individual workers having specialized tasks. The output produced by

\footnotetext{
${ }^{3}$ Topel (1982) and Haltiwanger and Maccini (1988) describe the interrelated responses of labor demand and inventory holdings to changes in product demand. In addition, Topel addresses the joint determination of employment adjustment technology and inventory holding technology.

${ }^{4}$ For example, production worker employment in the canned fruits and vegetables industry (SIC 2033)--the most variable industry studied--varies, on average, 300 percent from trough to peak each year.

${ }^{5}$ Indivisibility constraints imposed by the technology (e.g. workers can not simultaneously operate multiple machines less intensively) cause firms to operate incompletely staffed shifts with some machines in use and otherwise identical machines idle. For example, Shapiro (1995) finds that shirt-producing plants in SIC 2321 commonly operate single shifts, but that multiple-shift plants use much larger first shifts.
} 
each worker is dependent on the output of the other workers on the assembly line. Because changing the number of production workers would require costly reorganization of the workers' specialized tasks, automobile assembly plants typically change output by changing hours per worker, rather than by changing either the number of workers on each shift or the number of shifts. ${ }^{6}$

Because there are no adequate controls for many of the industry-specific characteristics that affect the choice of adjustment costs, I focus on groups of industries that are relatively homogenous in terms of their output and production processes. ${ }^{7}$ I study the relationship at the four-digit level between the magnitude of fluctuations in labor demand and the size of the costs of adjusting employment within, rather than across, two-digit industries using adjustment costs for four-digit industries estimated as in Fleischman (1996). I consider 12 two-digit SIC manufacturing sectors: food and kindred products (SIC 20), textile mill products (SIC 22), apparel and other textile products (SIC 23), lumber and wood products (SIC 24), furniture and fixtures (SIC 25), chemicals and allied products (SIC 28), stone, clay, and glass (SIC 32), primary metals (SIC 33), fabricated metals (SIC 34), industrial machinery and equipment (SIC 35), electrical machinery (SIC 36), and transportation equipment (SIC 37). ${ }^{8}$

For each two-digit sector, I treat the four-digit industries as individual observations and regress the industries' estimated adjustment costs on their expected squared percentage changes in employment in the four-digit industries. In each two-digit industry, I find a negative relationship between adjustment costs and expected volatility in employment, suggesting that adjustment costs are lower in the four-digit industries where the benefits of lower adjustment costs are greatest. The results are statistically significant in eight of the

\footnotetext{
${ }^{6}$ Bresnahan and Ramey (1994) find that automobile assembly plants rarely change the number of shifts, and even more rarely change line speeds. One possible explanation for not changing the number of shifts is that union seniority rules require that the least senior workers at each plant be laid off first, necessitating costly reorganization of production teams if a shift is dropped. Instead, these plants change output by changing hours per worker, which includes the use of temporary layoffs where hours per worker are set to zero but workers remain attached to their plant and continue to receive more than 90 percent of their typical pay.

${ }^{7}$ Fleischman (1996), finds that adjustment costs are generally lower in nondurable goods industries than in durable goods industries, with adjustment costs lowest in food and kindred products (SIC 20) and apparel and other textiles (SIC 23) and highest in industrial machinery and equipment (SIC 35). It is unlikely that differences of the magnitudes observed can be explained merely by interindustry variation in labor demand fluctuations.

${ }^{8}$ The remaining two-digit manufacturing industries are excluded because they lack a sufficient number of four-digit industries with estimates of adjustment costs.
} 
industries, and are particularly strong for the food and kindred products industries--an industry for which production smoothing using final-goods inventory manipulations is generally not feasible--as well as for chemicals and allied products and stone, clay, and glass. In addition, I find some evidence that an industry's choice of adjustment costs is more closely related to the predictable seasonal variability in employment than it is to the stochastic variability in employment.

Following this introduction, the rest of the paper is organized as follows. In section II, I discuss the tradeoffs between efficiency and flexibility in the choice of production process, and derive the first-order condition for the choice of adjustment costs from an extension to the dynamic cost minimization model of Fleischman (1996). In section III, I discuss my strategy for estimating the terms of the tradeoff between efficiency and flexibility. In Section IV, I present the estimates of the relationship between the size of labor demand fluctuations and the choice of adjustment costs at the four-digit SIC level. In Section V, I conclude by discussing directions for future work. In Appendix A, I present a brief description of the identification and estimation of adjustment costs I used in Fleischman (1996).

\section{The Tradeoff Between Efficiency and Flexibility in the Choice of Adjustment Costs}

In this section, I extend the model of Fleischman (1996) to allow for endogenous adjustment costs. I build upon the insights in Stigler (1939), Fuss and McFadden (1978), and Beaulieu, et al. (1992) that firms consider the nature of fluctuations in the demand for their output in trading off efficiency against flexibility in their choice of production process. While these authors concentrate on the relative costs of producing at different output levels using two different production processes, I also consider dynamic aspects of the tradeoff because firms with variable output are concerned both with the costs of producing at different levels, and the costs of adjusting productive inputs to meet their changing output goals.

As in Fleischman (1996), I treat each four-digit manufacturing industry as a 
representative firm that produces gross output, $\mathrm{Y}_{\mathrm{iv}}$, according to: ${ }^{9}$

$$
Y_{i t}=F\left(G\left(L_{i t}, H_{i t}\right), N_{i t}, K_{i t}, M_{i t}, E_{i t}\right) \epsilon_{i t}
$$

where $\mathrm{i}$ indexes industries and $\mathrm{t}$ indexes time, $\mathrm{L}_{\mathrm{it}}$ is production worker employment, $\mathrm{H}_{\mathrm{it}}$ is hours per production worker, $\mathrm{N}_{\mathrm{it}}$ is non-production workers, $\mathrm{K}_{\mathrm{it}}$ is the capital stock, $\mathrm{M}_{\mathrm{it}}$ is materials, $E_{i t}$ is energy, $\epsilon_{i t}$ is the level of factor neutral technology, and $G\left(L_{i t}, H_{i t}\right)$ is production worker labor input. Assuming separability of the production function, a cost minimizing firm's allocation of total production worker hours, $\mathrm{L}_{\mathrm{i}} \mathrm{H}_{\mathrm{i}}$, among hours per worker and the number of production workers is independent of the factor prices and stocks of capital and non-production workers. I use a Cobb-Douglas function for production worker labor input:

$$
G\left(L_{i t}, H_{i t}\right)=L_{i t} H_{i t}^{\beta}
$$

where $\beta$ is the elasticity of production worker labor with respect to hours per worker. $\beta$ will be greater than one if there are significant setup or other fixed costs of starting work and less than one if workers tire. ${ }^{10}$

Firms can costlessly adjust hours per worker but incur adjustment costs in changing their production worker employment. Compensation per worker is equal to the sum of fringe benefits (components of compensation that are not tied explicitly to wages, including some benefits and employers' contributions to social insurance programs, such as unemployment insurance taxes and workers compensation premia) and wages (including benefits and contributions to social insurance that are tied to earnings, such as employer contributions to social security and Medicare taxes). The supply of production workers to each firm is elastic at the market rate of compensation per worker. The firm, however, internalizes a schedule of hourly wage rates that is increasing in the number of hours per worker because of the mandatory overtime premium: ${ }^{11}$

\footnotetext{
${ }^{9}$ Hamermesh (1989, 1993), Caballero and Engel (1993), Davis and Haltiwanger (1990, 1992), and Caballero, Engel, and Haltiwanger (1994) discuss the problems of spatial aggregation in the study of dynamic labor demand.

${ }^{10}$ See Estevão (1996) for a detailed analysis of the issues related to the estimation of $\beta$.

${ }^{11}$ I assume implicitly that the ratio of overtime hours to total hours per worker increases with the number of total hours per worker.
} 


$$
W_{i t}^{p}\left(H_{i t}\right)=W_{i t}^{b} *\left(1+0.5 \frac{O_{i t}}{H_{i t}}\right)
$$

where $\mathrm{W}_{\mathrm{it}}^{\mathrm{p}}$ is the hourly wage paid by the firm, $\mathrm{W}_{\mathrm{it}}^{\mathrm{b}}$ is the base wage (average hourly earnings excluding overtime), and $\mathrm{O}_{i t}$ is overtime hours. Combining fixed, per-worker fringe benefits and the wage schedule--equation (3)--leads to a roughly U-shaped hourly compensation relationship, so deviations of hours per worker from their optimal level are costly.

The costs of adjusting production worker employment are symmetric and quadratic in the (net) percentage change in production worker employment and proportional to production worker compensation. ${ }^{12}$ The choice of modeling adjustment costs as proportional to production worker compensation is driven largely by the absence of high-frequency output data for many of the four-digit industries. ${ }^{13}$ The adjustment cost parameter, $\gamma_{\mathrm{i}}$, is a summary statistic for many design features that can affect the efficiency and flexibility of production, including the degree of worker specialization, the capital-to-labor ratio, the minimum scale of production, and the plant size. Adjustment costs internal to the firm, including the costs associated with the reorganization of production, training costs, hiring costs, and separation costs, are all related to production worker compensation. Reorganization costs and training costs involve the costs of time that is not used for producing measurable output; hiring costs

\footnotetext{
${ }^{12}$ Hamermesh $(1989,1993,1995)$ discusses the shortcomings of the quadratic adjustment cost model. He argues that the quadratic adjustment cost model and its less structural analog, the partial adjustment model, fail to capture important features of plant level adjustment costs because these models predict smooth adjustment of employment to labor demand shocks, while actual plant level adjustments in employment are lumpy. He also argues that differences in the nature of fluctuations in labor demand, including differences in the persistence and variability of changes in labor demand, can affect the estimates of adjustment costs. This is exactly the point I explore in this paper. I examine whether industries with greater volatility in labor demand choose production processes with lower adjustment costs (i.e., production processes that allow them to react to changes in labor demand by varying employment relatively more than they vary hours per worker). Future work should focus on how the model of the choice of production process would change if one focused on the technology choice at the marginal plant(s) rather than at a representative firm.

${ }^{13}$ This specification follows Nickell (1986). Shapiro (1986) takes the alternative approach and includes the adjustment costs in the production function. Because output is measured net of adjustment costs and some factors are used in adjusting employment, this method better accounts for the output lost when firms adjust their factor inputs while excluding adjustment costs from the production function introduces systematic mismeasurement into the estimation of the parameters of the production function. However, when adjustment costs are identified from the marginal cost condition, the choice of specification is less important because costly adjustment affects marginal costs in both specifications.
} 
are likely to be proportional to compensation; ${ }^{14}$ and separation costs, including termination benefits, are generally functions of compensation. Hiring costs and separation costs can be directly accounted for in the firm's cash outflow, while the use of productive factors for reorganization and training reduces cash inflow. Each period, the firm incurs variable costs equal to: $:^{15}$

$$
V_{i t}=L_{i t} C_{i t}\left[1+\frac{\gamma_{i}}{=}\left(\Delta \log \left(L_{i t}\right)\right)^{2}\right]+A\left(\gamma_{i}\right) Y_{i t}
$$

where $V_{i t}$ is the variable costs, $C_{i t}$ is compensation per worker, and $A\left(\gamma_{i}\right)$ is the cost of choosing a particular set of plant characteristics that leads to adjustment costs, $\gamma_{\mathrm{i}} \mathrm{A}^{\prime}\left(\gamma_{\mathrm{i}}\right)<0$, and $\mathrm{A}^{\prime \prime}\left(\gamma_{\mathrm{i}}\right)>0$. The term, $\mathrm{A}\left(\gamma_{\mathrm{i}}\right) \mathrm{Y}_{\mathrm{it}}$, represents the loss of efficiency relative to the best available production process. Were it not for this efficiency cost, all firms would choose the minimum possible adjustment costs. The curvature restrictions on $\mathrm{A}\left(\gamma_{\mathrm{i}}\right)$ imply that plants that are designed to be efficient but not flexible (high $\gamma$ ) could add additional flexibility with only a small cost in terms of additional efficiency loss. Conversely, industries that have low adjustment costs (small $\gamma$ ) find that a small reduction in adjustment costs requires a relatively large additional efficiency loss.

Following Stigler (1939) and Fuss and McFadden (1978), I allow the efficiency loss to affect both marginal and average costs, thus abstracting away from issues relating to the interaction of the choice of production process and the nature of capacity growth in each fourdigit industry. Under this assumption, the efficiency loss associated with the choice of production technology, which may be a fixed cost at the plant level, grows in proportion to output at the industry level. This is consistent with industries growing (or contracting) primarily through increases (or decreases) in the number of firms (plants), rather than through

\footnotetext{
${ }^{14}$ Hamermesh (1993) surveys the literature that attempts to directly measures hiring and firing costs and finds that hiring and firing costs increase with skills and, therefore, with compensation.

${ }^{15}$ I suppress the contributions of materials and energy inputs to variable costs. Moreover, I treat nonproduction workers and the capital stock as fixed from month to month because these factors adjust substantially more slowly than either production worker employment or hours per worker. See Shapiro (1986) for estimates of the costs of adjusting capital, non-production worker employment, production worker employment, and hours per production worker. In addition, I assume separability of the production function and no cross adjustment terms in the cost function so that I can estimate the first-order conditions for hours per worker and production workers without high-frequency output and capital stock data. See Fleischman (1996) for a more complete discussion of the assumptions necessary to estimate adjustment costs without data on output and the capital stock.
} 
increases (or decreases) in capacity at existing plants. ${ }^{16}$ Furthermore, by treating the efficiency loss as a variable cost that depends on the level of output produced in each period, rather than as a fixed cost paid at the time the choice of production process is made or one that is payable evenly over each future period, implies that both the benefits of the flexibility of the production process and the costs associated with choosing a less than fully efficient production process accrue at the same rate. And, because the benefits and costs associated with this choice are discounted at the same rate, the tradeoff between efficiency and flexibility is independent of the rate at which the industry is growing or shrinking.

At the beginning of time, each firm chooses the adjustment cost parameter, $\gamma_{\mathrm{i}}$, and a time path for production worker employment and hours per production worker that minimizes the expected discounted stream of variable costs:

$$
\begin{aligned}
& \operatorname{Min}_{\gamma_{i},\left\{L_{i t}, H_{i t}\right\}} E_{0}\left[\sum_{t=0}^{\infty}\left(\frac{1}{(1+r)}\right) V_{i t}\right] \\
& \text { s.t. } \quad Y_{i t+s}=F\left(G\left(L_{i t+s}, H_{i t+s}\right), N_{i t+s}, K_{i t+s}, M_{i t}, E_{i t}\right) \epsilon_{i t+s} \\
& \quad G\left(L_{i t+s}, H_{i t+s}\right)=L_{i t+s} H_{i t+s}^{\beta} \\
& s=0,1,2, \ldots . .
\end{aligned}
$$

where $r$ is the constant real interest rate. The first-order conditions for production worker employment and hours per worker are:

$$
C_{i t}\left[1+\gamma_{i}\left[\frac{1}{2}\left(\Delta \log \left(L_{i t}\right)^{2}+\Delta \log \left(L_{i t}\right]\right]-E_{t}\left[R_{t+1} \frac{L_{i t+1}}{\frac{L_{i t}}{i t+1}} C_{i t} \gamma_{i} \Delta \log \left(L_{i t+1}\right)\right]=\left[\lambda_{i t}-A\left(\gamma_{i}\right)\right] \frac{\partial F_{i t}}{\partial G_{i t}} G\left(L_{i t}, H_{i t}\right) L_{i t}^{-1}\right.\right.
$$

and

\footnotetext{
${ }^{16}$ Modeling each industry as a representative firm constrains each plant within an industry--regardless of vintage--to have the same production process, as if industry growth occurred through the expansion or contraction of a single plant. Over time, however, firm entry and exit affects the composition of plants. Moreover, changes in the operating environment in the industry, especially those related to the volatility of labor demand, will influence which plants exit and the technology choices for entering plants. To deal with this issue explicitly, which I will not do in this paper, would require the derivation and estimation of a model of time-varying adjustment costs. Other studies of adjustment costs that use even more aggregated data than those used in this paper have not addressed this issue. Arguably, however, the changing composition of employment across industries will have larger effects on the adjustment costs than will the changing nature of employment fluctuations for a single four-digit manufacturing industry. Fleischman (1996) finds that changes in the industrial composition of employment have caused little intertemporal variation in adjustment costs for two-digit industries and aggregate manufacturing.
} 


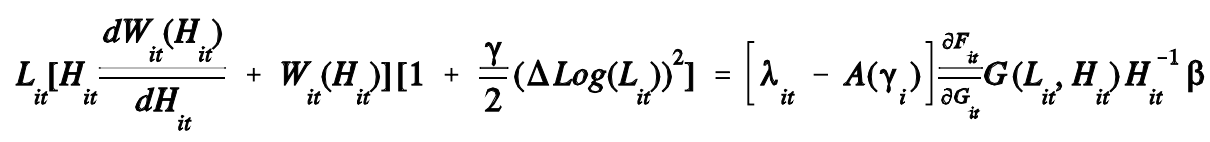

where $\partial \mathrm{F}_{\mathrm{t}} / \partial \mathrm{G}_{\mathrm{t}}$ is the marginal product of production worker labor; $\mathrm{W}_{\mathrm{it}}\left(\mathrm{H}_{\mathrm{it}}\right)$ is the hourly wage function (including benefits and contributions to social insurance that are tied to earnings); and $\lambda_{\mathrm{it}}$, the Lagrange multiplier on the production function constraint, plus $A\left(\gamma_{\mathrm{i}}\right)$ is marginal cost in period t. In Fleischman (1996) I solve the first-order conditions for production worker employment and hours per worker to obtain the equation used to estimate adjustment costs for production worker employment. ${ }^{17}$

Under the assumption of a one time choice of plant design, the first-order condition for the choice of adjustment cost parameter is:

$$
E_{0}\left[\sum_{t=0}^{\infty} R_{t} Y_{i t}\left[\frac{1}{2}\left(\Delta \log \left(L_{i t}\right)\right)^{2}\right]\right]=-E_{0}\left[\sum_{t=0}^{\infty} R_{t} Y_{i t} A^{\prime}\left(\gamma_{i}\right)\right]
$$

where $R_{t}$ is the cumulation of one-period interest rates. The left-hand-side of equation (8) is the marginal benefit of increased flexibility; the right-hand-side is the marginal cost of increased flexibility in terms of the loss of productive efficiency (or the increase in average cost). The greater the expected discounted volatility in employment (measured by the expected discounted stream of squared percentage changes in employment) the greater the marginal benefit to the firm of choosing lower adjustment costs; and, because greater flexibility comes at an increasingly large cost in terms of efficiency of production $\left(\mathrm{A}^{\prime}\left(\gamma_{\mathrm{i}}\right)<0\right.$, $\mathrm{A}^{\prime \prime}\left(\gamma_{\mathrm{i}}\right)>0$ ), the larger (in absolute value) will be the firms' marginal cost of additional flexibility.

The lack of high-frequency output data, however, leads me to replace output by total production worker compensation in equation (4):

$$
V_{i t}=L_{i t} C_{i t}\left[1+\frac{\gamma_{i}}{2}\left(\Delta \log \left(L_{i t}\right)\right)^{2}\right]+A\left(\gamma_{i}\right) L_{i t} C_{i t}
$$

Assuming the long-run cost share of production workers in total revenue is approximately constant, this substitution will have little effect on either the empirical results reported below or the conceptual discussion here. The first-order condition for the choice of adjustment cost

\footnotetext{
${ }^{17}$ I repeat this derivation, along with a description of the strategy for estimating adjustment costs, in Appendix A.
} 
parameter now becomes:

$$
E_{0}\left[\sum_{t=0}^{\infty} R_{t} L_{i t} C_{i t}\left[\frac{1}{2}\left(\Delta \log \left(L_{i t}\right)\right)^{2}\right]\right]=-E_{0}\left[\sum_{t=0}^{\infty} R_{t} L_{i t} C_{i t} A^{\prime}\left(\gamma_{i}\right)\right]
$$

Because $\gamma_{\mathrm{i}}$ is chosen at time 0 , I can take the unconditional expectations of both sides of equation $\left(8^{\prime}\right)$ and rewrite it as: ${ }^{18}$

$$
-A^{\prime}\left(\gamma_{i}\right)=\frac{E\left[\sum_{t=0}^{\infty} R_{t} L_{i t} C_{i t}\left[\frac{1}{2}\left(\Delta \log \left(L_{i t}\right)\right)^{2}\right]\right]}{E\left[\sum_{t=0}^{\infty} R_{t} L_{i t} C_{i t}\right]}
$$

Assuming that the covariance of the squared change in employment and with the level of production worker compensation in the numerator is finite, ${ }^{19}$ a sufficient condition for the existence of a solution to equation (9) for $\mathrm{A}^{\prime}\left(\gamma_{\mathrm{i}}\right)$ is that the terms inside the expectations in both the numerator and denominator grow at a finite rate.

\section{Estimation Strategy}

In this section, I discuss the strategy for estimating the parameters of $A^{\prime}\left(\gamma_{j}\right)$ by relating the adjustment cost parameter to the measure of employment variability on the righthand side of equation (9). Letting $U_{i}$ equal the ratio of the expectations on the right-hand side of equation (9), I restate the first-order condition for the choice of adjustment cost as:

$$
-A^{\prime}\left(\gamma_{i}\right)=U_{i}
$$

To use equation (10) to identify $\mathrm{A}^{\prime}\left(\gamma_{\mathrm{i}}\right)$, I assume that the range of production

\footnotetext{
${ }^{18}$ Note that because the size of the industry at any point in time--which I proxy by total production worker compensation-enters both the numerator and denominator of equation (9), the choice of adjustment costs is unaffected by the rate of growth of the industry.

${ }^{19}$ This unconditional covariance will have an annual periodicity due to the seasonal components in employment growth and in the level of production worker compensation. In addition, under the assumption that the unconditional expectations of the deterministic seasonality, the variance of stochastic employment shocks, and the trend in employment are independent of the time horizon, the seasonal covariance between production worker compensation and employment volatility will be the only covariance between these two terms.
} 
processes and the inventory holding technology are the same for the four-digit industries within each two-digit industry. Under these conditions, interindustry heterogeneity in $U_{i}$ traces out $\mathrm{A}^{\prime}\left(\gamma_{\mathrm{i}}\right)$ with more volatile industries choosing lower adjustment costs. This assumption implies that within a two-digit industry, only expected differences in employment volatility affect the marginal benefit of choosing a more flexible production process. ${ }^{20}$

I invert equation (10), expressing the choice of adjustment cost parameter as a function of $\mathrm{U}_{\mathrm{i}}$ :

$$
\gamma_{i}=-N\left(U_{i}\right.
$$

where $\mathrm{N}(\mathrm{l})=\mathrm{A}^{\prime-1}(\mathrm{)}$. I constrain the adjustment costs to be positive by considering:

$$
\log \left(\gamma_{i}\right)=\log \left(-N\left(U_{i}\right)\right.
$$

Because there is little information to suggest a parameterization for either $A^{\prime}\left(\gamma_{j}\right)$ or $N\left(U_{j}\right)$, I estimate a flexible functional form by taking a second order Taylor series expansion of (12) around $\mathrm{U}_{\mathrm{i}}^{*}$ :

$$
\log \left(\gamma_{i}\right) \approx \log \left(-N\left(U_{i}^{*}\right)\right)-\frac{N^{\prime}\left(U_{i}^{*}\right)}{N\left(U_{i}^{*}\right)}\left(U_{i}-U_{i}^{*}\right)-\left[\frac{N^{\prime \prime}\left(U_{i}^{*}\right)}{N\left(U_{i}^{*}\right)}-\left(\frac{N^{\prime}\left(U_{i}^{*}\right)}{N\left(U_{i}^{*}\right)}\right)^{2}\right]\left(U_{i}-U_{i}^{*}\right)^{2}
$$

After collecting terms, equation (13) reduces to:

$$
\log \left(\gamma_{i}\right) \approx-\left(N_{0}+N_{1} U_{i}+N_{2}\left(U_{i}^{2}\right)+e_{i}\right.
$$

where $\mathrm{N}_{0}, \mathrm{~N}_{1}$, and $\mathrm{N}_{2}$ are now parameters to be estimated and $\mathrm{e}_{\mathrm{i}}$ is a specification error. The specification error arises from interindustry differences across the four-digit industries within each two-digit industry in inventory holding costs, sets of feasible production processes, or other factors that can affect the terms of the tradeoff between efficiency and flexibility.

Assuming that both production worker employment and per worker compensation follow geometric trends with both deterministic seasonal and stochastic deviations $\left(\mathrm{L}_{\mathrm{t}}=\right.$ $\mu_{1}{ }^{\mathrm{t}} \mathrm{s}_{1 \mathrm{jt}} \mathrm{v}_{1 \mathrm{t}}$ and $\mathrm{C}_{\mathrm{t}}=\mu_{2}{ }^{\mathrm{t}} \mathrm{s}_{2 \mathrm{j}} \mathrm{v}_{2 \mathrm{t}}$ where $\mu_{1}$ and $\mu_{2}$ are the growth rates of employment and

\footnotetext{
${ }^{20}$ This assumption, which is the best available, may be violated in practice if there is sufficient variation within a two-digit industry in the storability of products produced or in the nature of production processes available. It is, however, untestable. No data on the range of possible production processes are available, and high-frequency data on inventories are available only at the two- and three-digit industry levels. Nevertheless, this assumption is implicit in any study that aggregates across four-digit industries within two-digit industries.
} 
compensation; $\mathrm{s}_{1 \mathrm{jt}}$ and $\mathrm{s}_{2 \mathrm{jt}}$ are the seasonal components; and $\mathrm{v}_{1 \mathrm{t}}$ and $\mathrm{v}_{2 \mathrm{t}}$ are the stochastic components), the series being summed in both the numerator and denominator can represented as the product of a deterministic geometric trend, which grows over time, and a periodic component due to deterministic seasonal and stochastic deviations from trend:

$$
\sum_{t=0}^{\infty} X_{t}=\sum_{t=0}^{\infty} \mu^{t} X_{t}^{*}
$$

where $X_{t}^{*}$ is the series of expectations, $\mu$ is the geometric rate of growth, and $X_{t}^{*}$ is the periodic component. I assume that there is no forecastibility around the deterministic components (trend and seasonals), which is consistent with the assumption of a one-time choice of production process made at the beginning of time. When the periodic component has a p-period frequency, the term within the expectation can be rewritten as:

$$
\begin{gathered}
\sum_{t=0}^{\infty} \mu^{t} X_{t}^{*}= \\
{\left[X_{0}^{*}+\mu X_{1}^{*}+\ldots \mu^{p-1} X_{p-1}^{*}\right]+} \\
\mu\left[X_{0}^{*}+\mu X_{1}^{*}+\ldots \mu^{p-1} X_{p-1}^{*}\right]+ \\
\mu^{2 p}\left[X_{0}^{*}+\mu X_{1}^{*}+\ldots \mu^{p-1} X_{p-1}^{*}\right]+\ldots \\
=\sum_{t=0}^{\infty} \mu^{p t}\left[X_{0}^{*}+\mu X_{1}^{*}+\ldots \mu^{p-1} X_{p-1}^{*}\right] \\
=\left(\frac{1}{1-\mu}\right)\left[X_{0}^{*}+\mu X_{1}^{*}+\ldots \mu^{p-1} X_{p-1}^{*}\right]
\end{gathered}
$$

Under these conditions, I can consistently estimate the expectations in the numerator and denominator by the sample means of the values inside the sums, up to a linear constant. I construct the period zero expectation of the discounted volatility measures using data on employment and wages from the establishment survey from the Bureau of Labor Statistics (BLS) and on compensation from the Bureau of Economic Analysis (BEA) for the 1972 to 1981 period. $^{21}$

The adjustment costs used in the left-hand side of equation (14) are similar to those

\footnotetext{
${ }^{21}$ The results are not sensitive to whether I use pre-sample information to construct expected volatility or whether I measure expected volatility over the same period I use to estimate adjustment costs.
} 
estimated in Fleischman (1996). ${ }^{22}$ I present both OLS and weighted least squares (WLS) estimates of equation (14). Because the left-hand-side variables in equation (14) are themselves regression estimates, I control for the heteroskedasticity in the residuals that arises from variations in the precision of the estimates of adjustment costs. The weights for the weighted least squares regressions are the variances of the estimated log adjustment costs. I found a strong positive relationship between the size of the estimate and its variance, so the weighted least squares estimates of $\mathrm{N}_{1}$ tend to be lower (less negative). I do not, however, correct the standard errors from these regressions to take into account the fact that the adjustment costs are estimated.

\section{Results}

In this section, I present empirical estimates of the relationship between expected employment volatility and the choice of adjustment costs. I report estimates of both the $\log$ quadratic approximation to $-\mathrm{A}^{\prime}\left(\gamma_{\mathrm{i}}\right)$ in equation (14) and a log-linear approximation $\left(\mathrm{N}_{2}=0\right)$ in the event that the quadratic specification may be overfitting the data.

Because of differences between the two-digit SIC industries in the sets of feasible production processes and in the ability to use inventory holdings to smooth production, I estimate the relationship between the magnitude of fluctuations in labor demand and the size of the costs of adjusting employment within, rather than across, two-digit industries. ${ }^{23}$ The key identifying assumptions are that for the four-digit industries within each two-digit industry, the terms of the tradeoff between efficiency and flexibility are substantially the same because these industries face a similar range of possible production processes and inventory holding technologies.

\footnotetext{
${ }^{22}$ Appendix A describes the estimation of adjustment costs using the first-order conditions for production worker employment and hours per worker and an auxiliary equation linking hours worked and overtime hours worked. The estimates of adjustment costs used in this paper were estimated using the manufacturing producer price index (PPI) rather than the industryspecific PPI used in Fleischman (1996). This increased the sample of industries from 126 to 229 with only trivial effects on the estimates of adjustment costs.

${ }^{23}$ For example, the available technology and storability of output differ significantly, for example, between the fabricated metal industries (SIC 34) and the apparel industries (SIC 23). Even two seemingly similar industries, the textile industry (SIC 22) and the apparel industry, have substantially different production processes (Murray 1995).
} 
In Table 1, I present summary statistics from the estimates of adjustment costs in 229 four-digit manufacturing industries. ${ }^{24}$ I present the number of four-digit industries with valid estimates, the median and mean adjustment costs among the four-digit industries, and the 25th and 75th percentile estimates of adjustment costs for durable goods producers, nondurable goods producers, and each of the following 12 two-digit manufacturing industries. ${ }^{25}$

Table 1 shows substantial heterogeneity in adjustment costs both across and within the two-digit industries. The within-industry variation in adjustment costs is particularly large in food and kindred products, primary metal industries and transportation equipment; in these industries the interquartile ranges are more than three times the size of the 25 th percentile estimate of adjustment costs. Other two-digit industries with substantial variation in adjustment costs include textile mill products, lumber and wood products, chemicals and allied products, industrial machinery and equipment, and electrical machinery, where the interquartile ranges are at least one and a half times as large as the 25 th percentile estimates.

In Table 2, I present OLS and weighted least squares ${ }^{26}$ (WLS) estimates of the parameters of the log linear approximation to the marginal cost of flexibility function, $\mathrm{A}^{\prime}\left(\gamma_{\mathrm{j}}\right)$. The tradeoff between efficiency and flexibility described above predicts a negative relationship between adjustment costs and expected employment volatility. Thus, the coefficient on expected volatility of employment, $\mathrm{N}_{1}$, should be negative. Table 2 shows that the OLS and WLS estimates of $\mathrm{N}_{1}$ are negative in all 12 two-digit industries, and that the OLS (WLS) estimates are statistically significant at better than the 10 percent level in eight (five) of the industries. In the OLS (WLS) regressions, interindustry heterogeneity in the variability of employment explains more than 25 percent of the interindustry variation in adjustment costs in seven (five) of the two-digit industries studied. In food and kindred

\footnotetext{
${ }^{24}$ Data limitations, estimation problems, and the exclusion of continuous process industries reduced the sample from 450 to 229 four-digit manufacturing industries. See Fleischman (1996) for a discussion of these issues. See Appendix A for a discussion of the estimation of adjustment costs in the four-digit industries.

${ }^{25}$ The table includes only two-digit industries with at least nine four-digit industries with valid estimates. Of the 229 fourdigit industries shown in the all industries line, 200 are classified within the 12 two-digit industries examined here. I exclude the two-digit industries with fewer four-digit industries because these two-digit industries lack sufficient variation to estimate the relationship between adjustment costs and employment volatility.

${ }^{26}$ The weights for the weighted least squares regressions are the variances of the estimated log adjustment costs. I found a strong positive relationship between the size of the estimate and its variance, so the weighted least squares estimates of $\mathrm{N}_{1}$ tend to be lower (less negative).
} 
products, chemicals and allied products, stone, glass, and clay and industrial equipment and machinery, the $\mathrm{R}^{2}$ is substantially higher for the WLS regressions than for the OLS regressions, suggesting that imprecisely estimated outliers were a particular problem in these industries. In contrast, OLS fits the data somewhat better in apparel and other textiles, electrical equipment, and transportation equipment.

Figures 1 to 6 show graphically the regression results for the six industries where the model fits best: ${ }^{27}$ food and kindred products, textile mill products, chemicals and allied products, stone, clay, and glass, industrial machinery and equipment, and electronic and other electrical equipment. Each figure shows a nonlinear, downward sloping relationship between adjustment costs and expected employment volatility. ${ }^{28}$ The small number of four-digit industries within each two-digit industry raises the concern that much of the downward sloping relationship is driven by one influential observation. This is of particular concern in food and kindred products, where the industry with the greatest expected employment volatility--canned fruits and vegetables--is nearly seven times more volatile than the next most volatile industry. Excluding the most volatile four-digit industry in each two-digit industry, however, qualitatively changes the results only for chemicals and allied products; the estimates of $\mathrm{N}_{1}$ change from significant and negative to insignificant and positive.

Table 3 presents OLS and WLS estimates of the quadratic approximation to the inverse of $\mathrm{A}^{\prime}\left(\gamma_{\mathrm{i}}\right)$. The table reports estimates of the constant, linear, and quadratic terms and the estimated slope of the adjustment cost function evaluated at the mean of expected employment volatility for each two-digit industry. ${ }^{29}$ After allowing for additional curvature, the estimated slope of the adjustment cost function is negative in 11 of the 12 industries; only chemicals and allied products has a positive slope. The negative slopes are statistically significant at the 10 percent level in three industries using OLS and four industries using WLS. In general, because of the small sample sizes, the results from the linear specification

\footnotetext{
${ }^{27}$ I chose these six industries because they each had statistically significant estimates of $\mathrm{N}_{1}$ in the OLS regressions and at least marginally significant estimates of $\mathrm{N}_{1}$ in the WLS regressions. I omitted transportation equipment (SIC 37) because the WLS estimate of $\mathrm{N}_{1}$ shown in Table 2 has a t-statistic of only 1.0.

${ }^{28}$ The estimated equations are linear in the expected employment volatility and the log of adjustment costs.

${ }^{29}$ The results are nearly identical when the median of employment volatility for each two-digit industry replaces the mean.
} 
should be preferred.

Under the assumption that expectations of the trend, stochastic, and seasonal components of employment growth are independent, it is possible to decompose the expectations of the square of the percentage change in employment into three components: the square of the trend growth rate, the variance of the stochastic component of employment growth, and the square of the seasonal employment growth rates. In Table 4, I report estimates of the parameters of the linear approximation to the inverse adjustment cost function when the independent variable is just the seasonal variability in employment growth. ${ }^{30}$ Seasonality in labor demand might be particularly important in firms' plant design decisions. Barsky and Miron (1989), Beaulieu et al. (1992), and Cecchetti, Kashyap, and Wilcox (1995) show that seasonal and stochastic variations in key macroeconomic time series are related. Beaulieu et. al. (1992) argue that these relationships can be explained by firms with larger seasonal fluctuations choosing greater capacity that allows them to accommodate large cyclical fluctuations. The results in Table 4 suggest that firms consider seasonal volatility in choosing their adjustment costs. The OLS and WLS estimates of $\mathrm{N}_{1}$ are negative in all twelve industries and statistically significant in seven and five industries, respectively. Moreover, compared with the results for total expected employment volatility shown in Table 2, deterministic seasonal volatility can explain approximately the same or larger percentage of the variance in adjustment costs in nine of the two-digit industries in the OLS and WLS regressions.

Stochastic volatility appears somewhat less important in explaining the variation in adjustment costs. Table 5 reports the estimates of the parameters of the inverse adjustment cost function when the independent variables are the variance of the stochastic component of labor demand--defined as the variance of the residuals in the regression of the percentage change in employment on monthly dummy variables. The OLS and WLS estimates of $\mathrm{N}_{1}$ are significantly negative in five and three of the two-digit industries, respectively. In addition, expected stochastic volatility explains a smaller percentage of the variation in adjustment

\footnotetext{
${ }^{30}$ The seasonal factors are constructed by squaring the demeaned dummy variable coefficients from a regression of the change in employment on 12 monthly dummies.
} 
costs than the full measure of expected employment volatility in six of the two-digit industries.

Generally, the results from the three measures of employment variability are consistent, showing a negative relationship between employment variability and adjustment costs. In most of the two-digit industries, adjustment costs are high in the four-digit industries with low variability of employment. The small sample sizes of the regressions, however, makes strong interpretations difficult. To address this issue, I pooled across the two-digit industries and reestimated the adjustment cost function using all 229 four-digit industries for which estimates of adjustment costs are available. The results for each specification are presented in the last row of tables 2 to 5 . I constrain the estimates of $\mathrm{N}_{1}$ (and $\mathrm{N}_{2}$ in the quadratic specifications) to be the same across all two-digit industries, but estimate separate intercept terms in place of the constant, $\mathrm{N}_{0}$. Both the OLS and the WLS estimates are quite precise, and the estimated parameters each have the expected sign. In the quadratic specifications, where overfitting is no longer an issue, the slope of the marginal cost function can vary across industries. The resulting estimated relationship between employment volatility and adjustment costs is convex, so that the tradeoff is steeper for industries with less volatile employment.

The results presented in this section suggest strongly that there is a tradeoff between efficiency and flexibility in the choice of production process. However, some important caveats remain. The terms of the tradeoff between production efficiency and employment flexibility may depend on characteristics of the industries in addition to the amplitude of labor demand fluctuations. Additional factors, including interindustry differences in the nature of output produced and in the storability of output, are subsumed in the $A^{\prime}\left(\gamma_{j}\right)$ function. Identification of the terms of the tradeoff, however, rests on the homogeneity of available production processes and the similarity of inventory holding costs among the four-digit industries within each two-digit industry. Topel (1982) and Haltiwanger and Maccini (1988) describe the interrelated responses of labor demand and inventory holdings to changes in product demand, and Topel addresses the joint determination of employment adjustment technology and inventory holding technology. Firms that find it excessively costly or impossible to hold buffer stocks of final goods inventories, because of either the nature of 
their raw inputs (e.g., food industries) or the nature of their outputs (e.g., fashion industries), must react to changes in input costs or product demand by varying output, and, hence, labor input. These firms have strong incentives to choose production processes with relatively low costs of adjusting employment. Conversely, firms that produce more fungible or storable goods can vary inventory holdings in response to transitory changes in product demand in order to smooth production. If the four-digit industries within a particular two-digit industry produce sufficiently different types of goods (i.e., apparel industries produce both specialty fashion items that cannot be stored from year to year and commodity type items that are quite storable), then the assumption of a constant relationship between employment volatility and the marginal benefit of additional flexibility is likely to be violated. When this assumption is violated, the terms of the tradeoff between efficiency and flexibility are not identified.

\section{Conclusions}

In this paper, I develop and estimate a model of endogenous adjustment costs. The model builds on the insights in Stigler (1939), Fuss and McFadden (1978), and Beaulieu et al. (1992) that firms that operate in industries with variable product demand value flexibility in production. I extend the notion of a tradeoff between efficiency and static flexibility to encompass the additional tradeoff between efficiency and dynamic flexibility. I argue that firms that face variable product demand consider the costs of moving between different levels of production, as well as the costs of producing different levels of output.

I model the choice of production process as a one-time event at the beginning of time. The first-order condition for the choice of the parameter controlling the costs of adjusting production worker employment equates the expected marginal cost of additional flexibility-the reduced efficiency of producing a given level of output--to the expected marginal benefit of additional flexibility--the reduced cost of changing levels of production. Under the assumption that the effect of expected employment volatility on the marginal benefit of additional flexibility is the same for all four-digit industries within a particular two-digit industry, interindustry differences in employment volatility identify the model.

Generally, the relationship between adjustment costs and employment volatility is 
negative and significant. The results are quite consistent across the different specifications for the twelve two-digit industries. This model, however, is only a first step at characterizing the extent to which industries with highly volatile employment have lower costs of adjusting employment. Future work should address the possibility that the terms of the tradeoff between efficiency and flexibility vary within two-digit industries. This can be accomplished by more fully modeling the firm's choice of production process, including a simultaneous determination of adjustment costs and inventory holding costs. The ability to use intermediate or final goods inventories to smooth production is an important determinant of the terms the tradeoff between efficiency and flexibility.

In addition to the overall finding that interindustry variation in expected employment volatility can explain much of the variation in adjustment costs, I find that interindustry heterogeneity in the amplitude of deterministic seasonal fluctuations in employment explains more of the variation in adjustment costs than does heterogeneity in the variance of the stochastic component of employment fluctuations. Seasonal fluctuations, because they are predominantly non-stochastic, may be fundamentally different from non-seasonal fluctuations. Future work should address the question of whether the marginal seasonal and non-seasonal workers are performing the same jobs and have the same skills. If within an industry, workers' skills vary substantially over the year, this might argue for modeling production as a peak-load process rather than as a single process that is rescaled as production varies over the year. In either case, the insight that the firm's environment influences its choice of production process would remain valid. The issue of the seasonal variability in the skill-mix of production workers is also closely related to the nature of adjustments at the plant level, because the choice of adjustment costs described is this paper is essentially a plant level decision. Another useful area for future work is to rederive the model under the assumption of non-convex adjustment costs and retest the model using plant level data. 


\section{Appendix A}

I obtain estimates of adjustment costs for four-digit SIC manufacturing industries using the model that I developed in Fleischman (1996). In Fleischman (1996), I solve the firstorder conditions for production worker employment and hours per production worker from a dynamic cost minimization problem--equation (5)--for marginal cost. The first-order conditions, shown as equations (6) and (7) above, are: ${ }^{31}$

$$
\begin{gathered}
C_{i t}\left[1+\gamma_{i}\left[\frac{1}{2}\left(\Delta \log \left(L_{i t}\right)^{2}+\Delta \log \left(L_{i t}\right]\right]-E_{t}\left[R_{t+1} \frac{L_{i t+1}}{L_{i t}} C_{i t+1} \gamma_{i} \Delta \log \left(L_{i t+1}\right)\right]\right.\right. \\
\left.=\left[\lambda_{i t}-A\left(\gamma_{i}\right)\right]\right]_{\frac{\partial i t}{\partial G_{i t}}}^{\frac{\partial F_{i t}}{2}}\left(L_{i t}, H_{i t}\right) L_{i t}^{-1}
\end{gathered}
$$

and

$$
L_{i t}\left[H_{i t} \frac{d W_{i t}\left(H_{i t}\right)}{d H_{i t}}+W_{i t}\left(H_{i t}\right)\right]\left[1+\frac{\gamma}{2}\left(\Delta \log \left(L_{i t}\right)\right)^{2}\right]=\left[\lambda_{i t}-A\left(\gamma_{i}\right)\right]{\frac{j}{\partial G_{i t}}}_{\partial F_{i t}} G\left(L_{i t}, H_{i t}\right) H_{i t}^{-1} \beta
$$

These first-order conditions can both be solved for marginal cost-- $\lambda_{i t}+A\left(\gamma_{i}\right)$--and the resulting expressions set equal:

$$
\begin{gathered}
\frac{\gamma_{i} L_{i t} C_{i t}}{\frac{\partial F_{i t}}{\partial G_{i t}} G\left(L_{i t}, H_{i t}\right)}\left[1+\left[\frac{1}{2}\left(\Delta \log \left(L_{i t}\right)^{2}+\Delta \log \left(L_{i t}\right)\right]-E_{t}\left[R_{t+1} \frac{C_{i t+1}}{C_{i t}} \frac{L_{i t+1}}{L_{i t}} \Delta \log \left(L_{i t+1}\right)\right]\right]\right. \\
=\frac{L_{i t} H_{i t}}{\beta \frac{\partial F_{i t}}{\partial G_{i t}} G\left(L_{i t}, H_{i t}\right)}\left[H_{i t} \frac{d W_{i t}\left(H_{i t}\right)}{d H_{i t}}+W_{i t}\left(H_{i t}\right)\right]\left[1+\frac{\gamma_{i}}{2}\left(\Delta \log \left(L_{i t}\right)\right)^{2}\right]
\end{gathered}
$$

The left-hand side of (A.3) is marginal cost measured when the number of production workers is varied and the other factors are held at their cost minimizing levels; the right-handside is defined analogously for hours per worker. The specifications of the production function and production worker input allow simplification of equation (A.3). The marginal

\footnotetext{
${ }^{31}$ In these first-order conditions, marginal cost is equal to $\lambda_{\text {it }}+\mathrm{A}\left(\gamma_{\mathrm{i}}\right)$; in Fleischman (1996), marginal cost is equal to $\lambda_{\text {it }}$ The additional term, $\mathrm{A}\left(\gamma_{\mathrm{i}}\right)$, which measures the tradeoff between efficiency and flexibility, is omitted.
} 
physical product of production worker employees can be written as the product of the marginal product of production workers times production worker labor input times the change in production worker labor input with respect to production worker employees. An analogous condition holds for the marginal physical product of hours per worker. Thus, in equating marginal costs in (A.3), all of the terms of the marginal products except $\mathrm{L}_{\mathrm{it}}{ }^{-1}$ and $\beta \mathrm{H}_{\mathrm{it}}{ }^{-1}$ drop out:

$$
\begin{aligned}
& {\left[\gamma E_{t}\left[\frac{1}{r_{t+1}} \frac{C_{i t+1}}{C_{i t}} \frac{L_{i t+1}}{L_{i t}} \Delta \log \left(L_{i t+1}\right)\right]-\gamma \Delta \log \left(L_{i t}\right)\right]+} \\
& {\left[\frac{1}{\beta} \frac{\left[H_{i t}^{2} \frac{d W_{i t}\left(H_{i t}\right)}{d H_{i t}}+H_{i t} W_{i t}\left(H_{i t}\right)\right]}{C_{i t}}-1\right]\left[1+\frac{\gamma}{2}\left(\Delta \log \left(L_{i t}\right)\right)^{2}\right]=0}
\end{aligned}
$$

Using equation (3), which showed the relationship between hourly wages, hourly wages excluding overtime, weekly hours, and weekly overtime hours that the BLS uses in constructing these data, I derive the marginal wage--the change in weekly wages in response to a change in weekly hours--as:

$$
\begin{gathered}
\frac{d\left(W_{i t}^{p}\left(H_{i t} O_{i t}\left(H_{i t}\right)\right) H_{i t}\right)}{d H_{i t}}=\frac{1}{2} H_{i t} W_{i t}^{b}\left[\frac{\frac{d O_{i t}\left(H_{i t}\right)}{d H_{i t}}}{H_{i t}}-\frac{O_{i t}}{H_{i t}^{2}}\right]+H_{i t} W_{i t}^{p}\left(H_{i t}\right) \\
=\frac{1}{2} H_{i t} W_{i t}^{b} \frac{O_{i t}}{H_{i t}^{2}}\left[\eta_{i}-1\right]+H_{i t} W_{i t}^{p}\left(H_{i t}\right)
\end{gathered}
$$

where $\eta_{\mathrm{i}}$--the only unknown parameter in the marginal wage function--is the constant elasticity of overtime hours with respect to average weekly hours. ${ }^{32}$ To obtain an estimable equation, I substitute equation (A.5) into (A.4) and replace the unobserved period $t$ expectation of period $t+1$ variables with:

$$
R_{t+1} \frac{C_{i t+1}}{C_{i t}} \frac{L_{i t+1}}{L_{i t}} \Delta \log \left(L_{i t+1}\right)=E_{t}\left[R_{t+1} \frac{C_{i t+1}}{C_{i t}} \frac{L_{i t+1}}{L_{i t}} \Delta \log \left(L_{i t+1}\right)\right]+\epsilon_{i t+1}
$$

\footnotetext{
${ }^{32}$ I approximate the shape of the marginal wage schedule under the assumption that the elasticity of overtime hours with respect to weekly hours is constant. The data were unable to support more elaborate specifications of this relationship used by Shapiro (1986) and Bils (1987).
} 
where $\epsilon_{\mathrm{it}+1}$ is a rational expectations innovation that is serially uncorrelated and has expectation, $E\left[\epsilon_{i t+1} \mid I_{t}\right]=0$, conditional on the $I_{\mathfrak{t}}$, the information set available to the agents in period t. After making the substitution and dividing the equation through by $\gamma_{\mathrm{i}} \mathrm{I}$ obtain the main relationship to be estimated: ${ }^{33}$

$$
\begin{gathered}
R_{t+1} \frac{C_{i t+1}}{\underline{C_{i t}}} \frac{L_{i t+1}}{L_{i t}} \Delta \log \left(L_{i t+1}\right)-\Delta \log \left(L_{i t}\right) \\
+\frac{1}{\gamma_{i}}\left[\frac{1}{\beta} \frac{\left[O_{i t} W_{i t}^{b}[\eta-1]+H_{i t} W_{i t}\left(H_{i t}\right)\right]}{C_{i t}}\right]\left[1+\frac{\gamma_{i}}{2}\left(\Delta \log \left(L_{i t}\right)\right)^{2}\right]-\frac{1}{\gamma_{i}}\left[1+\frac{\gamma_{i}}{2}\left(\Delta \log \left(L_{i t}\right)\right)^{2}\right]=\epsilon_{i t+1}
\end{gathered}
$$

I add an auxiliary equation linking the percentage change in overtime hours to the percentage change in weekly hours:

$$
\Delta \log \left(O_{i t}\right)=e_{0}+\eta \Delta \log \left(H_{i t}\right)+\zeta_{i t}
$$

I jointly estimate equations (A.7) and (A.8) using a generalized method of moments (GMM) estimator that allows for conditional heteroskedasticity. I use monthly dummy variables and a quadratic time trend as instruments in equation (A.8). The instruments for equation (A.7) are the monthly dummies and quadratic time trend, and aggregate (two-digit SIC industry) period t values of the log difference in employment and its square, the level of weekly hours and its square, the level of weekly overtime hours and its square, the percentage change in real hourly earnings and real hourly earnings excluding overtime, and the squared percentage change in production worker employment interacted with the quadratic time trend. The results are generally robust to changes in the instruments, but not to renormalization of the estimating equation. See Fleischman (1996) for a discussion of this point.

In the estimation, I use monthly data from the BLS establishment survey for production worker employment, weekly hours per production worker, weekly overtime hours per production worker, and average weekly earnings in each of the four-digit manufacturing

\footnotetext{
${ }^{33}$ In Fleischman (1996), I examine the sensitivity of the estimates of adjustment costs to the choice of parameter normalization. I find that the estimates from an alternative normalization where the adjustment cost parameter multiplies the rational expectations error, $\epsilon_{t+1}$, are economically trivial and often more than an order of magnitude smaller than those reported in this chapter. I also compare the two sets of GMM estimates to quasi-maximum-likelihood (QML) estimates. The QML estimates are robust to changes in normalization and economically, as well as statistically, similar to the GMM estimates reported here.
} 
industries; monthly data from BLS producer price index (PPI) for the manufacturing sector (results are insensitive to using the industry-specific PPI or the manufacturing sector PPI, but using the manufacturing sector PPI allows estimation of adjustment costs in a wider range of industries for a longer sample period); and annual data on total labor compensation in twodigit manufacturing industries from the BEA. I subtract wages and salaries and impute employer contributions for social security and medicare from total compensation to obtain nonwage benefits not tied directly to hours worked. I convert the annual data to monthly data by assuming that nominal benefits are constant over the year. I estimate benefits in the fourdigit industries relative to benefits in the relevant two-digit industry by assuming that they follow the same cubic trend as weekly wages in the four-digit industries relative to weekly wages in the relevant two-digit industry. See Fleischman (1996) for a complete discussion of the data. 


\section{References}

Barsky, Robert B. and Jeffrey A. Miron. "The Seasonal Cycle and the Business Cycle." Journal of Political Economy. 97:503-534.

Beaulieu, J. Joseph, Jeffrey K. MacKie-Mason, and Jeffrey A. Miron. 1992. "Why Do Countries and Industries with Large Seasonal Cycles Also Have Large Business Cycles?" Quarterly Journal of Economics. 107:621-656.

Bils, Mark. 1987. "The Cyclical Behavior of Marginal Cost and Price." American Economic Review, 77:838-855.

Bresnahan, Timothy F. and Valerie A. Ramey. 1994. "Output Fluctuations at the Plant Level." Quarterly Journal of Economics. 106:593-624.

Caballero, Ricardo J. and Eduardo M. R. A. Engel. 1993. "Microeconomic Adjustment Hazards and Aggregate Dynamics." Quarterly Journal of Economics. 108: 359-384.. and John Haltiwanger. 1994. "Aggregate Employment Dynamics: Building from Microeconomic Evidence." Unpublished.

Cecchetti, Stephen G., Anil K. Kashyap, and David W. Wilcox. "Do Firms Smooth the Seasonal in Production in a Boom? Theory and Evidence." NBER Working Paper No. 5011

Davis, Steven J. and John Haltiwanger. 1990. "Gross Job Creation and Destruction: Microeconomic Evidence and Macroeconomic Implications." in Olivier J. Blanchard and Stanley Fischer, eds. NBER Macroeconomics Annual 1990. Cambridge, MA: MIT Press.

and __ . 1992. "Gross Job Creation, Gross Job Destruction, and Employment Reallocation." Quarterly Journal of Economics. 107:819-863.

Estevão, Marcello. 1996. "Measurement Error and Time Aggregation: A Closer Look at Estimates of Output-Labor Elasticities." Board of Governors of the Federal Reserve System: Finance and Economics Discussion Series, 96-2.

Fleischman, Charles A. 1996. Heterogeneous Employment Adjustment Costs in U.S. Manufacturing Industries. Doctoral Dissertation, University of Michigan.

Fuss, Melvyn and Daniel McFadden. 1978. "Flexibility Versus Efficiency in Ex Ante Plant Design." in Melvyn Fuss and Daniel McFadden, editors. Production Economics: A Dual Approach to Theory and Applications, Volume 1. New York: North-Holland 
Publishing Company.

Haltiwanger, John C. and Louis J. Maccini. 1988. "A Model of Inventory and Layoff Behavior Under Uncertainty." The Economic Journal. 98:731-745.

Hamermesh, Daniel S. 1989. "Labor Demand and the Structure of Adjustment Costs." American Economic Review. 79:674-89.

. 1993. Labor Demand. Princeton, NJ: Princeton University Press.

. 1995. "Labour Demand and the Structure of Adjustment Costs." The Economic Journal. 105: 620-634.

Murray, Lauren A. 1995. "Unraveling Employment Trends in Textiles and Apparel." Monthly Labor Review, 118,8:62-72.

Nickell, Stephen. 1986. "Dynamic Models of Labor Demand." In Orley Ashenfelter and Richard Layard, eds., Handbook of Labor Economics. Amsterdam: North-Holland Press.

Shapiro, Matthew D. 1986. "The Dynamic Demand for Capital and Labor." Quarterly Journal of Economics, 101:513-42.

. 1995. "Capital Utilization and the Marginal Premium for Work at Night." Unpublished. University of Michigan.

Stigler, George. 1939. "Production and Distribution in the Short Run." Journal of Political Economy, 47:305-357. Reprinted in A.E.A. Readings in the Theory of Income Distribution. Homewood, IL: American Economic Association.

Topel, Robert. 1982. "Inventories, Layoffs and the Short-run Demand for Labor." American Economic Review. 72:769-87. 


\begin{tabular}{|l|c|c|c|c|c|}
\hline \multicolumn{5}{|c|}{ Table 1 } \\
\multicolumn{1}{|c|}{ Summary Statistics: Estimates of Adjustment Costs } \\
\hline Two Digit Industry (SIC Code) & $\begin{array}{c}\text { Number } \\
\text { of Four } \\
\text { Digit } \\
\text { Industries }\end{array}$ & Median & Mean & Percentile & percentile \\
\hline Food and Kindred Products (20) & 21 & 4.39 & 6.32 & 1.83 & 8.22 \\
\hline Textile Mill Products (22) & 15 & 7.18 & 8.36 & 5.50 & 12.58 \\
\hline Apparels and other Textiles (23) & 21 & 6.23 & 6.69 & 3.75 & 7.99 \\
\hline Lumber and Wood Products (24) & 14 & 3.82 & 4.32 & 2.34 & 5.73 \\
\hline Furniture and Fixtures (25) & 9 & 6.57 & 7.27 & 5.60 & 7.16 \\
\hline Chemicals and Allied Products (28) & 9 & 7.38 & 11.52 & 5.90 & 18.34 \\
\hline Stone, Clay, and Glass Products (32) & 16 & 5.11 & 5.88 & 3.06 & 6.99 \\
\hline Primary Metal Industries (33) & 9 & 11.69 & 19.94 & 6.97 & 38.12 \\
\hline Fabricated Metal Products (34) & 26 & 9.23 & 19.71 & 5.72 & 18.92 \\
\hline Industrial Machinery and Equipment (35) & 25 & 16.17 & 25.04 & 8.89 & 28.18 \\
\hline Electronic and other Electrical Equipment (36) & 22 & 9.54 & 11.96 & 5.82 & 15.05 \\
\hline Transportation Equipment (37) & 13 & 4.77 & 13.48 & 3.54 & 18.53 \\
\hline Manufacturing Industries & 229 & 7.19 & 13.24 & 4.42 & 15.14 \\
\hline Non-Durable Goods Industries & 87 & 6.88 & 10.67 & 3.79 & 13.11 \\
\hline Durable Goods Industries & 142 & 7.75 & 14.82 & 4.99 & 16.35 \\
\hline
\end{tabular}

Notes for table 1:

The median, 25th percentile, and 75th percentile values are the estimates for a particular four digit-industry. Mean adjustment cost is the unweighted average of adjustment costs for the four-digit industries within in the two-digit industry. The adjustment costs are estimated using the current instruments (monthly dummy variables, a quadratic time trend, and two-digit SIC level values of the percentage changes in real hourly earnings and real hourly earnings excluding overtime, levels and squares of the percentage changes in production worker employment, weekly hours per worker, and weekly overtime hours per worker). A full set of estimates for the fourdigit industries is presented in Fleischman (1996). 
Table 2

Adjustment Cost Function (Linear Approximation)

$\log \left(\gamma_{\mathrm{i}}\right)=\mathrm{N}_{0}+\mathrm{N}_{1} * 10^{3} \mathrm{U}_{\mathrm{i}}+\mathrm{e}_{\mathrm{i}}$

\begin{tabular}{|c|c|c|c|c|c|c|}
\hline & \multicolumn{3}{|c|}{ Ordinary Least Squares } & \multicolumn{3}{|c|}{ Weighted Least Squares } \\
\hline $\begin{array}{l}\text { Two-Digit } \\
\text { Industry } \\
\text { (NOBS) }\end{array}$ & $\begin{array}{c}\mathrm{N}_{0} \\
\text { (Std. Error) }\end{array}$ & $\begin{array}{c}\mathrm{N}_{1} \\
\text { (Std. Error) }\end{array}$ & $\begin{array}{c}\mathrm{R}^{2} \\
\left(\text { Adj. } \mathrm{R}^{2} \text { ) }\right.\end{array}$ & $\begin{array}{c}\mathrm{N}_{0} \\
\text { (Std. Error) }\end{array}$ & $\begin{array}{c}\mathrm{N}_{1} \\
\text { (Std. Error) }\end{array}$ & $\begin{array}{c}\mathrm{R}^{2} \\
\left(\operatorname{Adj} . \mathrm{R}^{2}\right)\end{array}$ \\
\hline 20 & 1.59 & -0.04 & 0.37 & 1.19 & -0.03 & 0.68 \\
\hline (21) & $\begin{array}{l}(0.21) \\
\end{array}$ & $\begin{array}{l}(0.01) \\
\end{array}$ & $(0.34)$ & $\begin{array}{l}(0.15) \\
\end{array}$ & $(0.00)$ & $\begin{array}{l}(0.67) \\
\end{array}$ \\
\hline 22 & 2.44 & $\begin{array}{l}-0.54 \\
\end{array}$ & 0.34 & 2.14 & $\begin{array}{l}-0.34 \\
\end{array}$ & 0.41 \\
\hline$(15)$ & $(0.20)$ & $(0.21)$ & $(0.29)$ & $(0.13)$ & $(0.11)$ & $(0.37)$ \\
\hline 23 & 1.88 & -0.11 & 0.27 & 1.55 & -0.08 & 0.09 \\
\hline (21) & $(0.20)$ & $\begin{array}{l}(0.04) \\
\end{array}$ & $(0.24)$ & $\begin{array}{l}(0.18) \\
\end{array}$ & $(0.06)$ & $\begin{array}{l}(0.04) \\
\end{array}$ \\
\hline 24 & 1.33 & -0.06 & 0.01 & 1.35 & -0.03 & 0.01 \\
\hline (14) & $(0.35)$ & $(0.18)$ & $(-0.07)$ & $(0.23)$ & $(0.11)$ & $(-0.07)$ \\
\hline 25 & 2.08 & $\begin{array}{l}-0.14 \\
\end{array}$ & 0.20 & 2.00 & $\begin{array}{l}-0.11 \\
\end{array}$ & 0.21 \\
\hline (9) & $(0.18)$ & $(0.11)$ & $(0.09)$ & $(0.13)$ & $(0.08)$ & $(0.10)$ \\
\hline 28 & 3.04 & -1.76 & 0.33 & 2.90 & -2.37 & 0.88 \\
\hline (9) & $(0.60)$ & $(0.96)$ & $(0.23)$ & $(0.32)$ & $(0.34)$ & $(0.86)$ \\
\hline 32 & 2.11 & -0.41 & 0.25 & 2.12 & -0.53 & 0.74 \\
\hline (16) & $(0.28)$ & $(0.19)$ & $(0.19)$ & $(0.19)$ & $(0.08)$ & $(0.72)$ \\
\hline 33 & 3.04 & -0.36 & 0.24 & 2.36 & -0.18 & 0.17 \\
\hline (9) & $(0.37)$ & $(0.24)$ & $(0.13)$ & $(0.24)$ & $(0.15)$ & $(0.05)$ \\
\hline 34 & 2.49 & -0.05 & 0.00 & 2.03 & -0.11 & 0.04 \\
\hline (26) & $(0.25)$ & $(0.20)$ & $(-0.04)$ & $(0.14)$ & $(0.11)$ & $(-0.00)$ \\
\hline 35 & 3.10 & -0.26 & 0.14 & 2.64 & -0.26 & 0.62 \\
\hline (25) & $(0.22)$ & $(0.14)$ & $(0.10)$ & $(0.10)$ & $(0.04)$ & $(0.60)$ \\
\hline 36 & 2.74 & -0.39 & 0.27 & 2.29 & -0.25 & 0.10 \\
\hline (22) & $(0.21)$ & $(0.15)$ & $(0.23)$ & $(0.26)$ & $(0.17)$ & $(0.05)$ \\
\hline 37 & 2.57 & -0.19 & 0.29 & 1.80 & $\begin{array}{l}-0.07 \\
\end{array}$ & 0.08 \\
\hline (13) & $(0.36)$ & $\begin{array}{l}(0.09) \\
\end{array}$ & $(0.22)$ & $(0.24)$ & $(0.07)$ & 0.00 \\
\hline All & & $\begin{array}{l}-0.05 \\
\end{array}$ & 0.40 & & -0.03 & 0.59 \\
\hline (229) & & $(0.01)$ & $(0.35)$ & & $(0.00)$ & $(0.55)$ \\
\hline
\end{tabular}

Notes to Table 2:

The dependent variable is the natural logarithm of adjustment costs estimated as in Fleischman (1996) using the current instruments. Weighted least squares regressions use the variance of the estimated adjustment costs as weights. The estimates using all 229 four-digit industries that are reported in the last two rows are from an equation with 17 two-digit SIC dummy variables and no constant. 


\begin{tabular}{|c|c|c|c|c|c|c|c|c|c|c|}
\hline \multicolumn{11}{|c|}{$\begin{array}{c}\text { Table 3 } \\
\text { Adjustment Cost Function (Quadratic Approximation) } \\
\log \left(\gamma_{\mathrm{i}}\right)=\mathrm{N}_{0}+\mathrm{N}_{1} * 10^{3} \mathrm{U}_{\mathrm{i}}+\mathrm{N}_{2} * 10^{6}\left(\mathrm{U}_{\mathrm{i}}\right)^{2}+\mathrm{e}_{\mathrm{i}}\end{array}$} \\
\hline & \multicolumn{5}{|c|}{ Ordinary Least Squares } & \multicolumn{5}{|c|}{ Weighted Least Squares } \\
\hline $\begin{array}{l}\text { Two-Digit } \\
\text { Industry } \\
\text { (NOBS) }\end{array}$ & $\begin{array}{l}\mathrm{N}_{0} \\
\text { (Std. } \\
\text { Error) }\end{array}$ & $\begin{array}{l}\mathrm{N}_{1} \\
(\mathrm{Std} . \\
\text { Error })\end{array}$ & $\begin{array}{l}\mathrm{N}_{2} \\
(\text { Std. } \\
\text { Error) }\end{array}$ & $\begin{array}{l}\text { Slope } \\
\text { (Std. } \\
\text { Error) }\end{array}$ & $\begin{array}{l}\mathrm{R}^{2} \\
(\mathrm{Adj} \\
\left.\mathrm{R}^{2}\right)\end{array}$ & $\begin{array}{l}\mathrm{N}_{0} \\
(\mathrm{Std} . \\
\text { Error) }\end{array}$ & $\begin{array}{l}\mathrm{N}_{1} \\
\text { (Std. } \\
\text { Error) }\end{array}$ & $\begin{array}{l}\mathrm{N}_{2} \\
(\text { Std. } \\
\text { Error })\end{array}$ & $\begin{array}{l}\text { Slope } \\
\text { (Std. } \\
\text { Error) }\end{array}$ & $\begin{array}{l}\mathrm{R}^{2} \\
(\text { Adj. } \\
\left.\mathrm{R}^{2}\right)\end{array}$ \\
\hline 20 & 1.91 & -0.17 & 0.00 & -0.17 & 0.52 & 1.44 & -0.13 & 0.00 & -0.13 & 0.74 \\
\hline$(21)$ & $(0.23)$ & $(0.06)$ & $(0.00)$ & $(0.06)$ & $(0.47)$ & $(0.19)$ & $(0.05)$ & $(0.00)$ & $(0.05)$ & $(0.71)$ \\
\hline 22 & 2.61 & $\begin{array}{l}-0.97 \\
\end{array}$ & 0.18 & -0.89 & 0.37 & 2.23 & -0.57 & 0.09 & -0.53 & 0.43 \\
\hline (15) & $(0.34)$ & $\overline{(0.70)}$ & $(0.28)$ & $(0.59)$ & $(0.26)$ & $\overline{(0.21)}$ & $(0.41)$ & $(0.16)$ & $(0.35)$ & $(0.33)$ \\
\hline 23 & 1.77 & -0.03 & -0.00 & -0.04 & 0.28 & 1.49 & -0.04 & -0.00 & -0.04 & 0.09 \\
\hline (21) & $(0.31)$ & $(0.18)$ & $(0.01)$ & $(0.17)$ & $(0.20)$ & $(0.26)$ & $(0.16)$ & $(0.01)$ & $(0.15)$ & $(-0.01)$ \\
\hline 24 & 2.38 & -1.78 & 0.43 & -1.45 & 0.34 & 2.13 & -1.34 & 0.34 & -1.09 & 0.22 \\
\hline (14) & $(0.54)$ & $(0.75)$ & $(0.18)$ & $(0.62)$ & $(0.22)$ & $(0.50)$ & $(0.76)$ & $(0.20)$ & $(0.61)$ & $(0.08)$ \\
\hline 25 & 2.28 & -0.50 & 0.08 & -0.45 & 0.28 & 2.19 & -0.48 & 0.08 & -0.43 & 0.27 \\
\hline (9) & $(0.32)$ & $\begin{array}{l}(0.47) \\
\end{array}$ & $(0.10)$ & $(0.41)$ & $(0.04)$ & $(0.29)$ & $(0.52)$ & $\begin{array}{l}(0.11) \\
\end{array}$ & $(0.45)$ & $(0.03)$ \\
\hline 28 & 1.64 & 3.90 & -4.24 & 2.75 & 0.67 & 1.90 & 1.84 & -2.79 & 1.08 & 0.97 \\
\hline (9) & $(0.73)$ & $\begin{array}{l}(2.40) \\
\end{array}$ & $(1.71)$ & $(1.96)$ & $(0.56)$ & $\begin{array}{l}(0.31) \\
\end{array}$ & $(1.08)$ & $(0.70)$ & $\begin{array}{l}(0.89) \\
\end{array}$ & $(0.95)$ \\
\hline 32 & 1.83 & 0.06 & -0.15 & -0.03 & 0.27 & 1.98 & -0.34 & -0.05 & -0.37 & 0.74 \\
\hline (16) & $(0.50)$ & $(0.73)$ & $(0.22)$ & $(0.60)$ & $(0.16)$ & $(0.40)$ & $(0.51)$ & $(0.13)$ & $(0.43)$ & $(0.70)$ \\
\hline 33 & 3.14 & -0.55 & 0.04 & -0.53 & 0.24 & 2.27 & -0.02 & -0.03 & -0.04 & 0.18 \\
\hline (9) & $(0.82)$ & $\begin{array}{l}(1.39) \\
\end{array}$ & $(0.31)$ & $(1.23)$ & $(-0.01)$ & $\begin{array}{l}(0.53) \\
\end{array}$ & $(0.84)$ & $(0.19)$ & $(0.74)$ & $(-0.10)$ \\
\hline 34 & 2.69 & -0.49 & 0.11 & -0.45 & 0.01 & 2.28 & -0.61 & 0.13 & -0.56 & 0.11 \\
\hline (26) & $(0.47)$ & $(0.88)$ & $(0.22)$ & $\begin{array}{l}(0.79) \\
\end{array}$ & $(-0.07)$ & $(0.24)$ & $(0.39)$ & $(0.09)$ & $(0.35)$ & $(0.03)$ \\
\hline 35 & 2.93 & 0.02 & -0.05 & -0.01 & 0.16 & 2.76 & -0.47 & 0.03 & -0.45 & 0.63 \\
\hline (25) & $(0.33)$ & $(0.42)$ & $(0.08)$ & $(0.38)$ & $(0.08)$ & $\begin{array}{l}(0.19) \\
\end{array}$ & $(0.29)$ & $(0.05)$ & $(0.26)$ & $(0.59)$ \\
\hline 36 & 3.27 & -1.21 & 0.21 & -1.08 & 0.36 & 2.92 & -1.18 & 0.28 & -1.01 & 0.23 \\
\hline (22) & $(0.38)$ & $\begin{array}{l}(0.51) \\
\end{array}$ & $(0.12)$ & $(0.43)$ & $(0.29)$ & $\begin{array}{l}(0.42) \\
\end{array}$ & $(0.53)$ & $(0.15)$ & $(0.44)$ & $(0.15)$ \\
\hline 37 & 3.09 & -0.70 & 0.06 & -0.62 & 0.37 & 2.11 & -0.37 & 0.04 & -0.32 & 0.17 \\
\hline (13) & $(0.57)$ & $(0.45)$ & $(0.05)$ & $(0.38)$ & $(0.24)$ & $\begin{array}{l}(0.39) \\
\end{array}$ & $(0.31)$ & $(0.04)$ & $(0.25)$ & $(0.00)$ \\
\hline All & & -0.18 & 0.00 & -0.18 & 0.46 & & -0.15 & 0.00 & -0.15 & 0.64 \\
\hline (229) & & $\begin{array}{l}(0.03) \\
\end{array}$ & $(0.00)$ & $\begin{array}{l}(0.03) \\
\end{array}$ & $(0.41)$ & & $(0.02)$ & $\begin{array}{l}(0.00) \\
\end{array}$ & $(0.02)$ & $\begin{array}{l}(0.60) \\
\end{array}$ \\
\hline
\end{tabular}

Notes to Table 3:

The dependent variable is the natural logarithm of adjustment costs estimated as in Fleischman (1996) using the current instruments. Weighted least squares regressions use the variance of the estimated adjustment costs as weights. The estimates using all 229 four-digit industries that are reported in the last two rows are from an equation with 17 two-digit SIC dummy variables and no constant. The estimated slope reported in the fourth and ninth columns is $\mathrm{N}_{1} * 10^{3}+2 * \mathrm{~N}_{2} * 10^{6 *} \mathrm{U}_{\mathrm{i}}$ evaluated at the mean value of $\mathrm{U}_{\mathrm{i}}$ within the two-digit industry; the standard errors are calculated using the delta method. 
Table 4

Adjustment Cost Function (Linear Approximation)--Seasonal Variation $\log \left(\gamma_{\mathrm{i}}\right)=\mathrm{N}_{0}+\mathrm{N}_{1} * 10^{3} \mathrm{U}_{\mathrm{i}}+\mathrm{e}_{\mathrm{i}}$

\begin{tabular}{|c|c|c|c|c|c|c|}
\hline & \multicolumn{3}{|c|}{ Ordinary Least Squares } & \multicolumn{3}{|c|}{ Weighted Least Squares } \\
\hline $\begin{array}{l}\text { Two-Digit } \\
\text { Industry } \\
\text { (NOBS) }\end{array}$ & $\begin{array}{c}\mathrm{N}_{0} \\
\text { (Std. Error) }\end{array}$ & $\begin{array}{c}\mathrm{N}_{1} \\
\text { (Std. Error) }\end{array}$ & $\begin{array}{c}\mathrm{R}^{2} \\
\left(\mathrm{Adj} . \mathrm{R}^{2} \text { ) }\right.\end{array}$ & $\begin{array}{c}\mathrm{N}_{0} \\
\text { (Std. Error) }\end{array}$ & $\begin{array}{c}\mathrm{N}_{1} \\
\text { (Std. Error) }\end{array}$ & $\begin{array}{c}\mathrm{R}^{2} \\
\left(\operatorname{Adj} . \mathrm{R}^{2}\right)\end{array}$ \\
\hline 20 & 1.56 & -0.05 & 0.36 & 1.18 & -0.04 & 0.68 \\
\hline (21) & $(0.21)$ & $\begin{array}{l}(0.01) \\
\end{array}$ & $(0.33)$ & $(0.15)$ & $(0.01)$ & $\begin{array}{l}(0.66) \\
\end{array}$ \\
\hline 22 & 2.22 & -0.67 & 0.15 & 1.98 & -0.40 & 0.15 \\
\hline$(15)$ & $(0.20)$ & $(0.45)$ & $(0.08)$ & $(0.14)$ & $(0.26)$ & $(0.09)$ \\
\hline 23 & 1.90 & -0.22 & 0.32 & 1.60 & -0.18 & 0.13 \\
\hline (21) & $(0.20)$ & $(0.07)$ & $(0.28)$ & $(0.18)$ & $(0.11)$ & $(0.08)$ \\
\hline 24 & 1.25 & -0.03 & 0.00 & 1.37 & -0.10 & 0.03 \\
\hline (14) & $(0.29)$ & $(0.28)$ & $(-0.08)$ & $(0.20)$ & $(0.19)$ & $(-0.06)$ \\
\hline 25 & 2.24 & -0.87 & 0.37 & 2.12 & -0.76 & 0.31 \\
\hline (9) & $(0.20)$ & $(0.43)$ & $(0.27)$ & $(0.16)$ & $(0.42)$ & $(0.21)$ \\
\hline 28 & 2.78 & -3.76 & 0.71 & 2.49 & -3.40 & 0.92 \\
\hline (9) & $(0.26)$ & $(0.91)$ & $(0.67)$ & $(0.22)$ & $(0.39)$ & $(0.90)$ \\
\hline 32 & 1.84 & -0.36 & 0.24 & 1.73 & -0.39 & 0.70 \\
\hline (16) & $(0.18)$ & $(0.18)$ & $(0.18)$ & $(0.15)$ & $(0.07)$ & $(0.68)$ \\
\hline 33 & 2.94 & -0.77 & 0.25 & 2.28 & -0.30 & 0.11 \\
\hline (9) & $(0.32)$ & $(0.51)$ & $(0.14)$ & $(0.22)$ & $(0.31)$ & $(-0.01)$ \\
\hline 34 & 2.57 & -0.38 & 0.04 & 2.02 & -0.21 & 0.06 \\
\hline (26) & $(0.21)$ & $(0.38)$ & $(0.00)$ & $(0.12)$ & $(0.18)$ & $(0.02)$ \\
\hline 35 & 2.95 & -0.37 & 0.14 & 2.51 & -0.30 & 0.58 \\
\hline (25) & $(0.18)$ & $(0.19)$ & $(0.10)$ & $\begin{array}{l}(0.09) \\
\end{array}$ & $(0.05)$ & $(0.56)$ \\
\hline 36 & 2.51 & -0.60 & 0.17 & 2.21 & -0.40 & 0.11 \\
\hline (22) & $(0.18)$ & $(0.30)$ & $(0.12)$ & $(0.19)$ & $(0.25)$ & $(0.07)$ \\
\hline 37 & 2.26 & -0.27 & 0.11 & 1.67 & -0.06 & 0.01 \\
\hline (13) & $(0.34)$ & $(0.22)$ & $(0.03)$ & $(0.20)$ & $(0.16)$ & $(-0.08)$ \\
\hline All & & -0.06 & 0.39 & & -0.04 & 0.58 \\
\hline (229) & & $(0.01)$ & $(0.35)$ & & $(0.00)$ & $(0.55)$ \\
\hline
\end{tabular}

Notes for Table 4:

The dependent variable is the natural logarithm of adjustment costs estimated as in Fleischman (1996) using the current instruments. Weighted least squares regressions use the variance of the estimated adjustment costs as weights. The estimates using all 229 four-digit industries that are reported in the last two rows are from an equation with 17 two-digit SIC dummy variables and no constant. Seasonal variation is the average of the coefficients from a regression of the squared percentage change in employment on monthly dummy variables. 
Table 5

Adjustment Cost Function (Linear Approximation)--Stochastic Variation

$\log \left(\gamma_{\mathrm{i}}\right)=\mathrm{N}_{0}+\mathrm{N}_{1} * 10^{3} \mathrm{U}_{\mathrm{i}}+\mathrm{e}_{\mathrm{i}}$

\begin{tabular}{|c|c|c|c|c|c|c|}
\hline & \multicolumn{2}{|c|}{ Ordinary Least Squares } & \multicolumn{3}{|c|}{ Weighted Least Squares } \\
\hline $\begin{array}{c}\text { Two-Digit } \\
\text { Industry } \\
\text { (NOBS) }\end{array}$ & $\begin{array}{c}\mathrm{N}_{0} \\
\text { (Std. Error) }\end{array}$ & $\begin{array}{c}\mathrm{N}_{1} \\
(\text { Std. Error) }\end{array}$ & $\begin{array}{c}\mathrm{R}^{2} \\
\left.\text { (Adj. } \mathrm{R}^{2}\right)\end{array}$ & $\begin{array}{c}\mathrm{N}_{0} \\
\text { (Std. Error) }\end{array}$ & $\begin{array}{c}\mathrm{N}_{1} \\
\text { (Std. Error) }\end{array}$ & $\begin{array}{c}\mathrm{R}^{2} \\
\text { (Adj. } \mathrm{R}^{2}\end{array}$ \\
\hline 20 & 1.85 & -0.40 & 0.30 & 1.36 & -0.49 & 0.43 \\
\hline$(21)$ & $(0.27)$ & $(0.14)$ & $(0.27)$ & $(0.24)$ & $(0.13)$ & $(0.40)$ \\
\hline 22 & 2.29 & -0.50 & 0.24 & 2.02 & -0.32 & 0.30 \\
\hline$(15)$ & $(0.19)$ & $(0.24)$ & $(0.19)$ & $(0.12)$ & $(0.13)$ & $(0.25)$ \\
\hline 23 & 1.83 & -0.20 & 0.13 & 1.45 & -0.06 & 0.01 \\
\hline$(21)$ & $(0.24)$ & $(0.12)$ & $(0.08)$ & $(0.19)$ & $(0.14)$ & $(-0.04)$ \\
\hline 24 & 1.40 & -0.17 & 0.02 & 1.27 & 0.02 & 0.00 \\
\hline$(14)$ & $(0.37)$ & $(0.30)$ & $(-0.06)$ & $(0.25)$ & $(0.18)$ & $(-0.08)$ \\
\hline 25 & 2.06 & -0.18 & 0.17 & 1.99 & -0.14 & 0.19 \\
\hline$(9)$ & $(0.18)$ & $(0.15)$ & $(0.05)$ & $(0.13)$ & $(0.11)$ & $(0.07)$ \\
\hline 28 & 2.11 & -0.06 & 0.00 & 2.07 & -3.13 & 0.22 \\
\hline$(9)$ & $(0.77)$ & $(1.87)$ & $(-0.14)$ & $(0.90)$ & $(2.21)$ & $(0.11)$ \\
\hline 32 & 1.60 & 0.01 & 0.00 & 0.77 & 0.50 & 0.11 \\
\hline$(16)$ & $(0.30)$ & $(0.32)$ & $(-0.07)$ & $(0.27)$ & $(0.38)$ & $(0.04)$ \\
\hline 33 & 3.08 & -0.44 & 0.25 & 2.41 & -0.24 & 0.21 \\
\hline$(9)$ & $(0.38)$ & $(0.29)$ & $(0.14)$ & $(0.25)$ & $(0.17)$ & $(0.10)$ \\
\hline 34 & 2.44 & 0.01 & 0.00 & 1.99 & -0.08 & 0.02 \\
\hline$(26)$ & $(0.23)$ & $(0.21)$ & $(-0.04)$ & $(0.14)$ & $(0.13)$ & $(-0.02)$ \\
\hline 35 & 3.00 & -0.18 & 0.05 & 2.71 & -0.42 & 0.59 \\
\hline$(25)$ & $(0.25)$ & $(0.17)$ & 0.00 & $(0.11)$ & $(0.07)$ & $(0.58)$ \\
\hline 36 & 2.74 & -0.47 & 0.26 & 2.11 & -0.16 & 0.02 \\
\hline$(22)$ & $(0.22)$ & $(0.17)$ & $(0.23)$ & $(0.26)$ & $(0.24)$ & $(-0.03)$ \\
\hline 37 & 2.56 & -0.19 & 0.28 & 1.78 & -0.06 & 0.07 \\
\hline$(13)$ & $(0.36)$ & $(0.09)$ & $(0.21)$ & $(0.23)$ & $(0.07)$ & $(-0.01)$ \\
\hline All & & -0.23 & 0.40 & & -0.27 & 0.46 \\
\hline$(229)$ & & $(0.05)$ & $(0.35)$ & & $(0.04)$ & $(0.41)$ \\
\hline
\end{tabular}

Notes for Table 5:

The dependent variable is the natural logarithm of adjustment costs estimated as in Fleischman (1996) using the current instruments. Weighted least squares regressions use the variance of the estimated adjustment costs as weights. The estimates using all 229 four-digit industries that are reported in the last two rows are from an equation with 17 two-digit SIC dummy variables and no constant. Stochastic variation is measured as the variance of the residual in a regression of the squared percentage change in production worker employment on monthly dummies. 


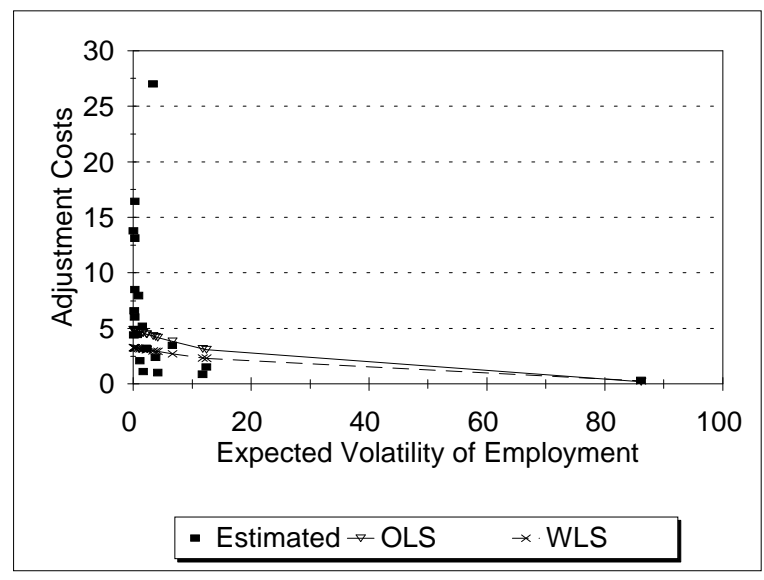

Figure 1

Endogenous Adjustment Costs--Food and Kindred Products (SIC 20)

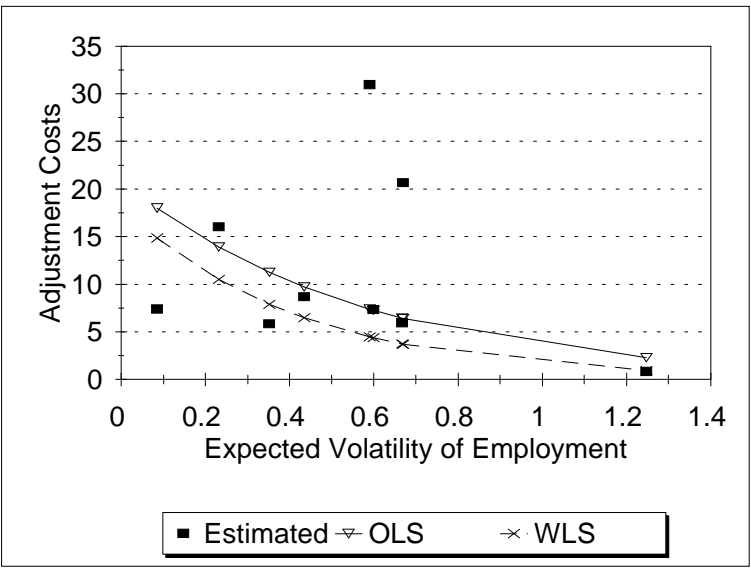

Figure 3

Endogenous Adjustment Costs--Chemicals and Allied Products (SIC 28)

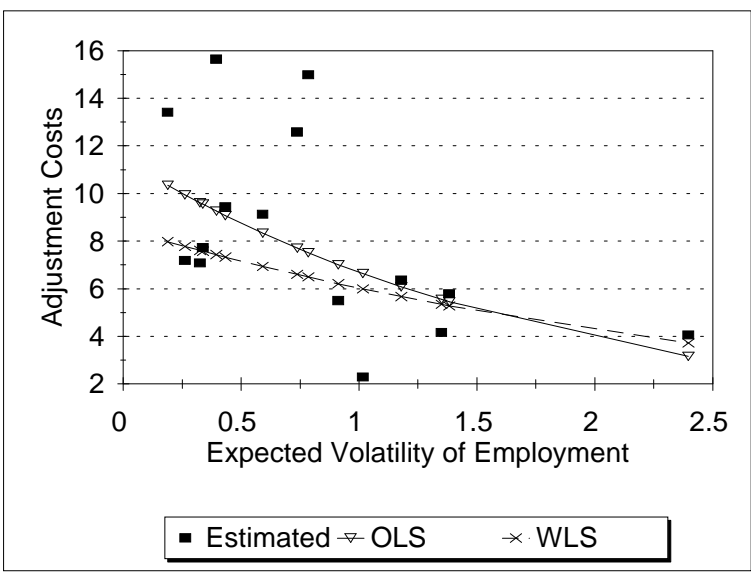

Figure 2

Endogenous Adjustment Costs--Textiles and other Mill Products (SIC 22)

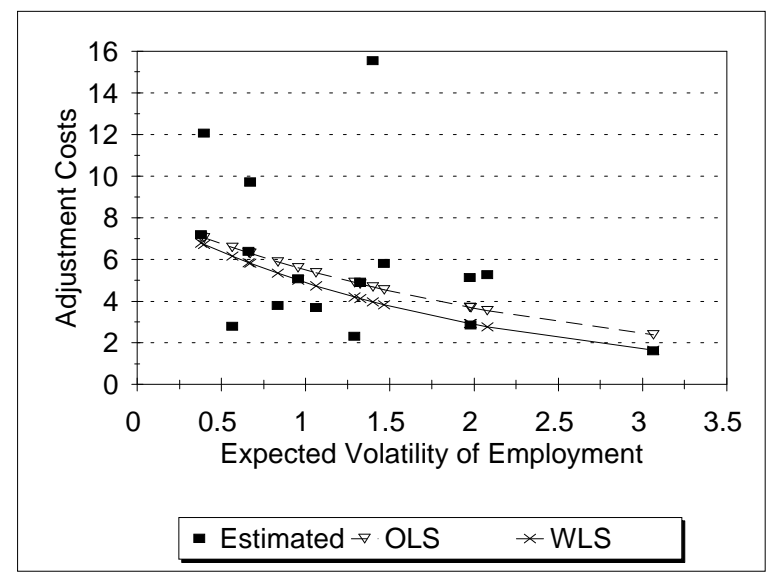

Figure 4

Endogenous Adjustment Costs--Stone, Clay, and Glass (SIC 32)

\footnotetext{
Notes for Figures 1 to 6 :

Adjustment costs are estimated as in Fleischman (1996) using the current instruments. Weighted least squares regressions use the variance of the estimated adjustment costs as weights.
} 


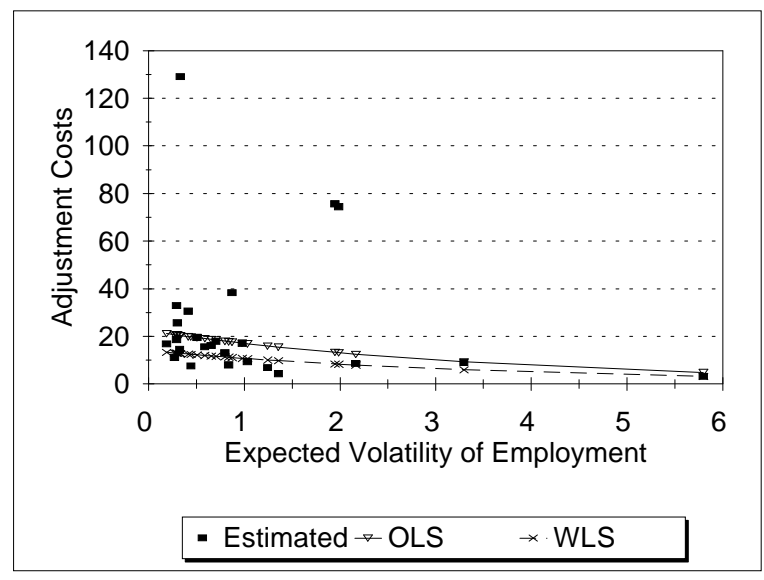

Figure 5

Endogenous Adjustment Costs--Industrial Machinery and Equipment (SIC 35)

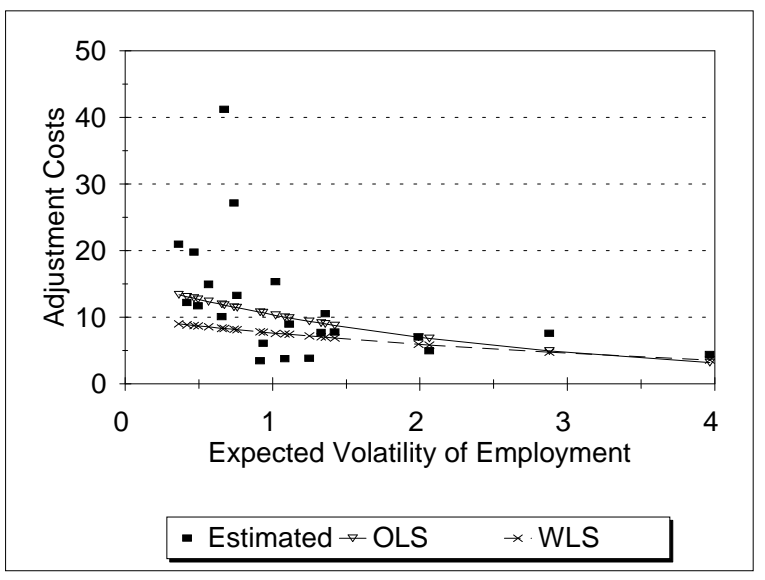

Figure 6

Endogenous Adjustment Costs--Electronic and Other Electrical Equipment (SIC 36) 